\title{
Optimum blasting with precision delays and true bottom hole initiation through e-DET-ft at Jayant Project of NCL
}

\author{
G Pandey, PK Sinha and CP Singh \\ Northern Coalfields Limited \\ Singrauli, India \\ prabhatranjan@idlind.com
}

\author{
P Ranjan \\ IDL Explosives Limited \\ Singrauli (India)
}

\begin{abstract}
Mining companies the world over are seriously looking at the 'total cost concept' having fully realized the benefits of good fragmentation and muckpile looseness achieved in the primary blasts itself. Good blast planning and accurate monitoring of the various operations holds the key to reaping and realizing the benefits. In the Mining or Construction Industry, one should look at the total cost of operations and not, in isolation, individual costs of drilling and blasting (which includes explosives and initiation system costs). Poor blast results have a cascading effect on the cost of downstream operations of loading, hauling, crushing (where applicable) and also associated aspects such as secondary blasting and slope stability.
\end{abstract}

Electronic detonators are extremely important tools for tomorrow's blasting needs in varied conditions for the reason they are precise in delay timing, field programmable, and much safer to use. They can reduce mining costs, when used technically correct. They can help mines in blast control and thus meet difficult environmental conditions with more productivity.

\section{Keywords_- fragmentation; Construction; environmental}

\section{ECONOMICS OF DRAGLINE OPERATIONS IN NCL}

Excavation operation by the draglines have the lowest cost per cum moved over the shovel-dumper system. It is the most cost effective method of removal of overburden as it involves no transport equipment. The cost of OB removal by Shovel-Dumper combination is more than double that of Dragline. This can be further reduced with effective planning, best work practices, effective operational and maintenance personnel and good front line Engineers.

Capital costs of Draglines are huge, i.e. large dragline 33/78R being erected in the NCL mine costs Rs. 183 Crores. Hence, draglines are required to be used efficiently and effectively to get return from the investment. The cost/cu.m of OB removal by dragline operation in NCL is around Rs.90 per cum and that by Shovel-Dumper is about Rs. 250/- This is comparable with cost of outsourcing for OB removal i.e. at Rs.80/cum approx. By increasing the capacity utilization of the dragline further, the cost of production will decrease further and may come below the cost of outsourcing, by optimizing the blast results and improving dragline performance to the desired level.

At present in NCL, electronic detonators are being used in Jayant Project, Dudhichua Project and Krishnashila project of NCL. The mines are now coming nearer to Singrauli town and Madhauli village. The mines are facing complaints about ground vibration and air blast overpressure from nearby residents and inhabitants. The expected life of Draglines is around 30 years or 140000 hours. In NCL, most of the Draglines have outlived their life. Thus, the frequency of breakdown of draglines and maintenance cost has become very- very high. NCL management is doing all it can to operate draglines.

\section{BLASTING FOR DRAGLINE}

For optimum utilization of dragline, proper fragmentation of overburden is very important. Blasting should be such that, adequate fragmentation is achieved along with loose muck-pile. In dragline benches of NCL, generally $311 \mathrm{~mm}$ diameter drills are used where bench height varies from $30 \mathrm{~m}$ to $40 \mathrm{~m}$. Therefore, blast should be designed, based on the bench height, diameter of the borehole, rock properties and properties of explosives. Usage of correct delay interval between drill holes is essential, to obtain proper fragmentation of overburden.

'Side-Casting of overburden by blasting is carried out in Dragline benches at times, by designing the blasts in such a manner that part of the blasted $\mathrm{OB}$ is thrown directly into the de-coaled area. By doing casting, substantial amount of cost is being saved through reduction in excavation and rehandling of overburden. Accuracy of firing times is a important necessity for success of cast blasts and use of electronic detonators ( $e$-DET $\mathrm{ft}$ ) assists in this regard.

Poor blast results of Dragline benches have adverse effects on productivity and costs of Dragline operations. Some of the effects are monitor various performance parameters and costs incurred for loading and hauling, such a detailed and in-depth study is still at a very nascent stage in Indian mining. 
A. e-DET ft - Electronic Delay Detonator :Indigenous Development of Energetics Division - GOCL Corporation Limited

Delay Detonators and Detonating Relays use pyrotechnic based delay element to generate a delay. The burning rate and the length of the element results in the various initiator firing times achieved. Pyrotechnic delays have an inherent problem of "scatter" viz. they fire either earlier or later than the specified 'nominal firing time'. With age, they become sluggish, causing a 'shift' in the timing.

1. High current drawn by motors causing deteriorations of Insulation

2. Higher stresses on drag machinery which leads to structural failures

3. Damage to the bucket

4. Breaking of Drag ropes

5. Increase of cycle time

\section{ELECTRONIC DetONATORS - E-DET “FT" - AN OVERVIEW}

$e$-DET "ft", fully field programmable electronic detonators manufactured by GOCL Corporation Limited (GOCL) and marketed by IDL Explosives Limited (IDLEL) is a new tool available to the users in the Indian scenario which helps the blasting engineer in carrying out optimum blasts. Currently in India, use of electronic detonators is primarily limited for carrying out cautious blasting, viz ground vibration and fly rock control. Even though there exists a strong scope of their use for optimum blasting by assigning the delay interval commensurate to the geomining conditions,

These drawbacks have been overcome with the pathbreaking development of the electronic delay detonator, where electronic microchips are used to provide very precise detonator firing times and the classical 'delay element' has been dispensed with. The detonators appear and function like the detonators currently being used. These detonators cannot be fired using conventional exploders. A set of coded signals has to be input to enable these detonators to fire.

In the Indian scenario, the Energetics Division of GOCL Corporation Limited has once again played a pioneering role by indigenously developing for the first time in the country through its own in-house technology and R\&D expertise, an electronic delay detonator under the brand name $\boldsymbol{e}$-DET ft. Figures $1 \mathrm{a}$ and $1 \mathrm{~b}$ give the details of pyrotechnic and electronic detonators (Ref: 2)

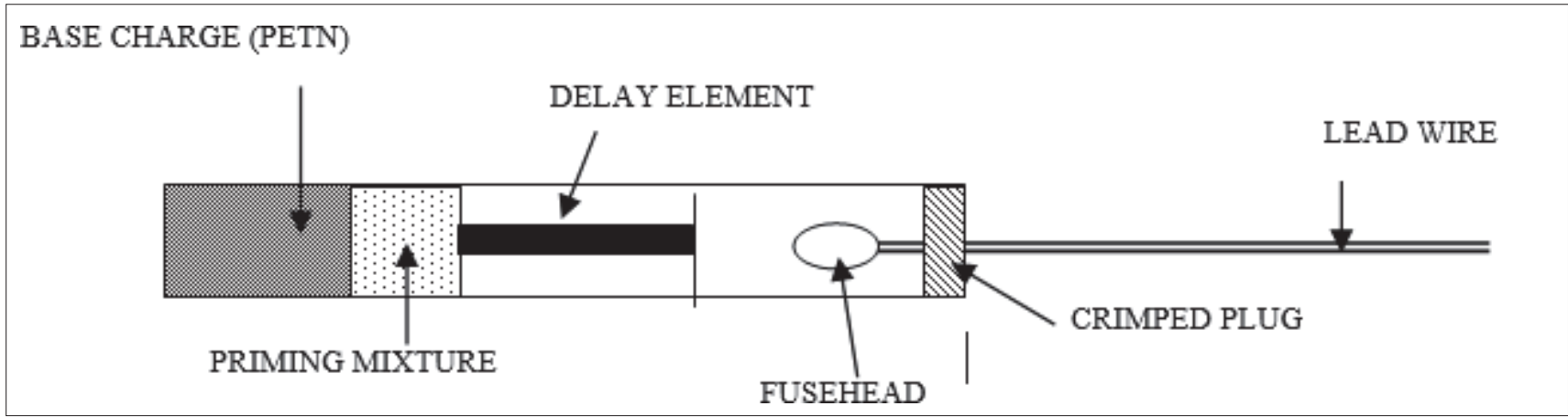

Fig.1a. A conventional Delay detonator

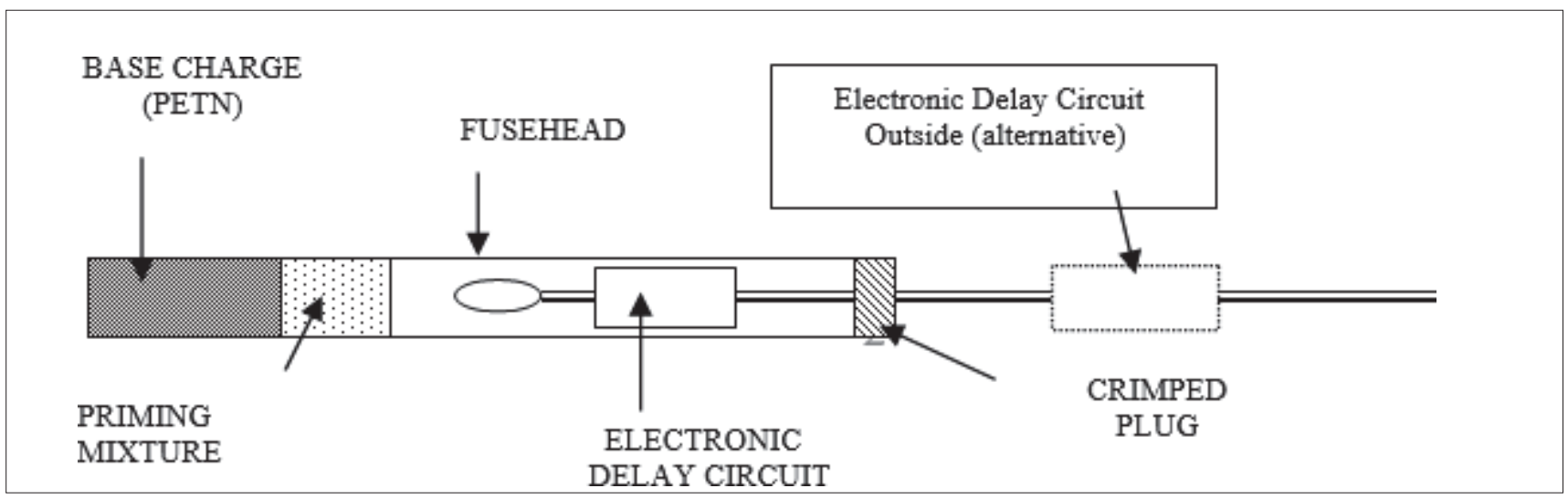

Fig. 1b. Electronic Detonator $e$-DET ft

\section{B. Fully field programmed}

All the drill holes in a blast are loaded with these detonators and the desired firing time of each detonator is logged in the field using a logger unit and later fired using an exploder. Detonators can be 'programmed' from 0 to 
9000 milliseconds (9 seconds), in increments of 1 millisecond.

The use of the programmable type of detonators described in Fig. 1b will provide tremendous flexibility to the users who wish to achieve the desired blast results by progressively changing the delay interval and arriving at the optimum delay 'specific to the site'.

The accurate firing times assists in achieving better fragmentation, muckpile looseness, and lower ground vibration levels in blasting. In tunnel blasting, the accurate timings will result in longer advance (pull), better contours and less damage to in-situ rock.

Use of $e$-DET " $\mathrm{ft}$ " offers the advantage of precise firing times, ability to programme the desired delay commensurate to need, besides true bottom hole initiation, causes no disturbance to the explosive column and keeps the stemming in place as the lead wires used for conveying the electric current to the detonator are non-disruptive.

The normally used drill hole initiation sequences such as Row delay, Diagonal pattern, V-pattern etc. are possible with $e$-DET "ft", as also field requirements requiring one drill hole to fire at a time and multi-hole blasts with TWO individual decks firing at separate delay intervals is also possible.

\section{A. e-DET ft system components:}

1. Field Circuit Tester: Handheld rechargeable battery operated unit to test the Detonator connection integrity after the field connections (Fig. 2a). This can test individual detonators or all detonators in a circuit in sequence.

2. Programmer Tester: Hand held rechargeable battery operated unit for programming the delay time and to identify the detonator number in the field (Fig. 2b). This unit is also used to test the functional integrity of the detonator and also to read the data programmed into it.

3. e-Xploder: Rechargeable Battery operated unit .It tests the functionality of $e$-DET $\mathrm{ft}$ in the field circuit before initiation. It powers the detonator and sends a signature signal to $e$-DET $\mathrm{ft}$ and instructs the detonators to initiate the start of delay (Fig. 2c). It allows aborting the firing sequence, if required.

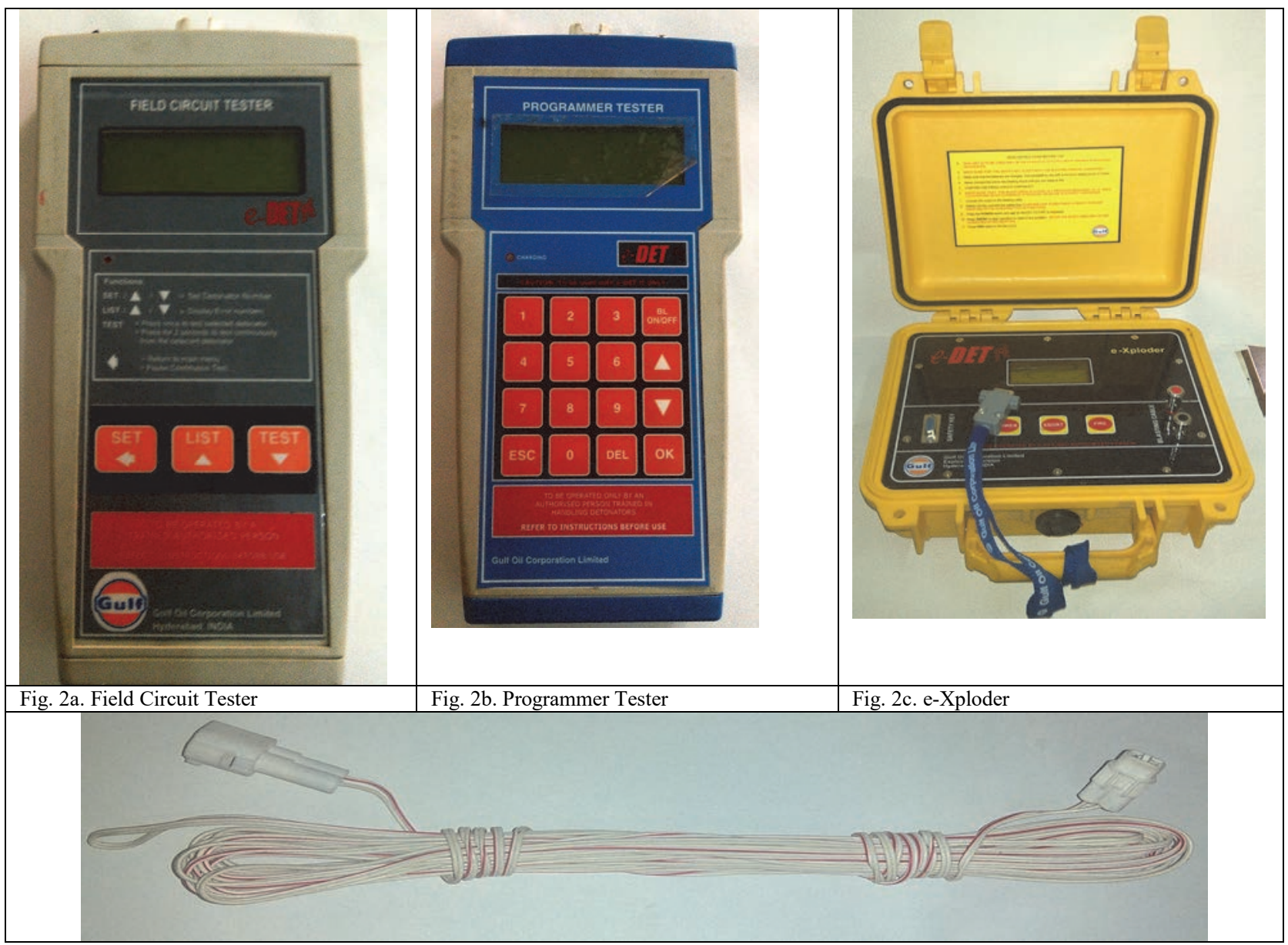

Fig. 2d. Surface Harness Wire 
B. e-DET ft (Field Programmable Electronic Detonator)

i) Specification:

- Maximum Delay timing: $9000 \mathrm{~ms}$

- Delay Interval resolution : $1 \mathrm{~ms}$ increments

- Scatter in delay : $\pm 0.02 \%$ of programmed delay or \pm 1 $\mathrm{ms}$ (whichever is higher)

- Detonator shell material : Brass

- Detonator shell diameter : $7.55 \mathrm{~mm}$

- Detonator Shell length : $90 \mathrm{~mm}$

- Lead wire material/Gauge : Twin copper wire/23 SWG

- Breaking Load of wire : $16 \mathrm{Kg}$

- Detonator strength : No.8

- Hydrostatic pressure test: Passes IS : 6609 Part III $2.1 \mathrm{~kg} / \mathrm{cm}^{2}$ for 2 hours

\section{ii) Connection:}

- Two wire polarised parallel connection

- Special waterproof connectors for easy field connections

- Pre-cut lengths of surface harness with factory assembled waterproof connectors (Fig. 2d)

\section{CASe Study - Jayant Project}

\section{A. Introduction of the Mine:}

Jayant Opencast mine is a 10 MTY project in NCL in which the excavation started in the year 1976-77 and the approximate depth of the mine is approaching 180 metres. The project is $3.6 \mathrm{~km}$ wide along strike length and the dip side length is $3.5 \mathrm{~km}$ whereas the average lead of the mine is $3.5 \mathrm{~km}$. The environmental clearance for annual coal production from the project is 15.5 MT.The rocks are of Lower Gondwana formation. There are three coal seams namely Turra, Purewa Bottom and Purewa Top.The thickness of the coal seams are $13-19 \mathrm{~m}, 9-12 \mathrm{~m}$ and 5-9 $\mathrm{m}$ respectively.The direction of strike is towards E-W with broad swings. The dip of the coal seam 1 Deg to 3 Deg in northerly direction. The total leasehold area is 2464 hectare. The mineable coal reserve of the mine is $348.90 \mathrm{Mt}$.The average stripping ratio is 2.6 cubic meter of overburden per tonne of coal.

Electronic detonators are being used first time on a regular basis in Dragline bench in Jayant project. The thickness of dragline bench varies from 30 to 40 metres. Singrauli town and Madhauli village are very near to Jayant project. The nearby inhabitants always used to complain about ground vibration and air overpressure due to Dragline blasts.

The Blasting Manager-Jayant OCP, General ManagerJayant OCP, GM (Production)-NCL and Director (Tech/OP)-NCL took decision to conduct Dragline blasts with electronic detonators, e-DET $\mathrm{ft}$, manufactured by GOCL Corporation Limited [1,2].

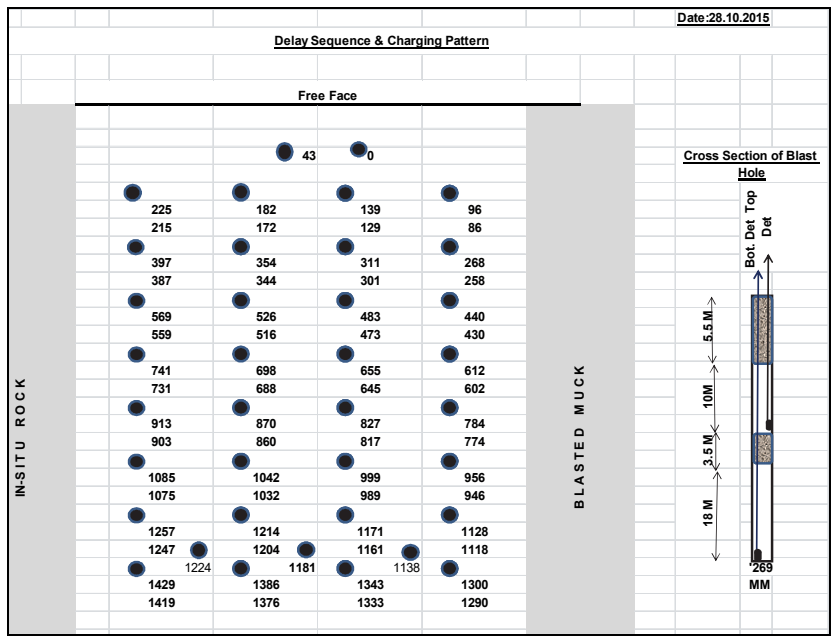

Fig. 3a. Delay sequence and changing pattern

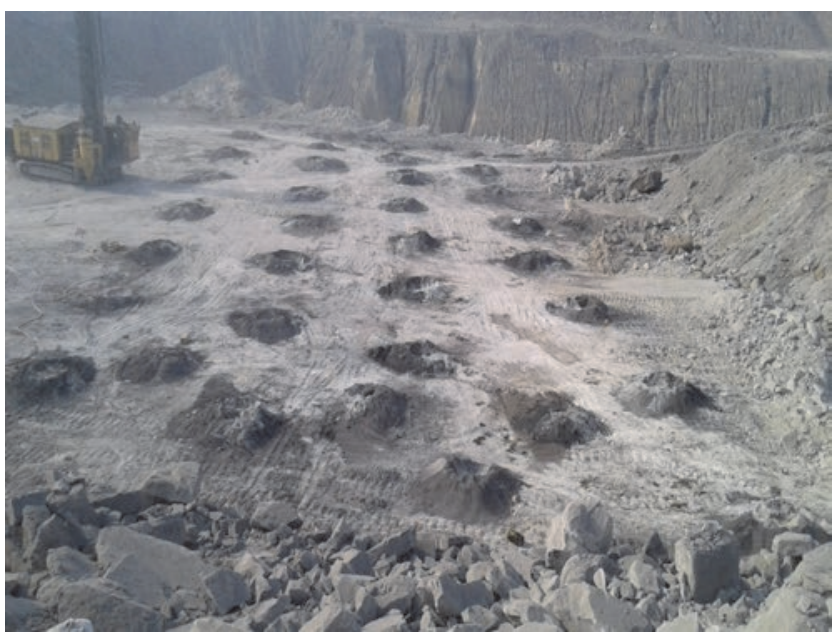

Fig. 3b. Pre blast picture of East Dl bench, Jayant Project blasted on dt.28.10.15

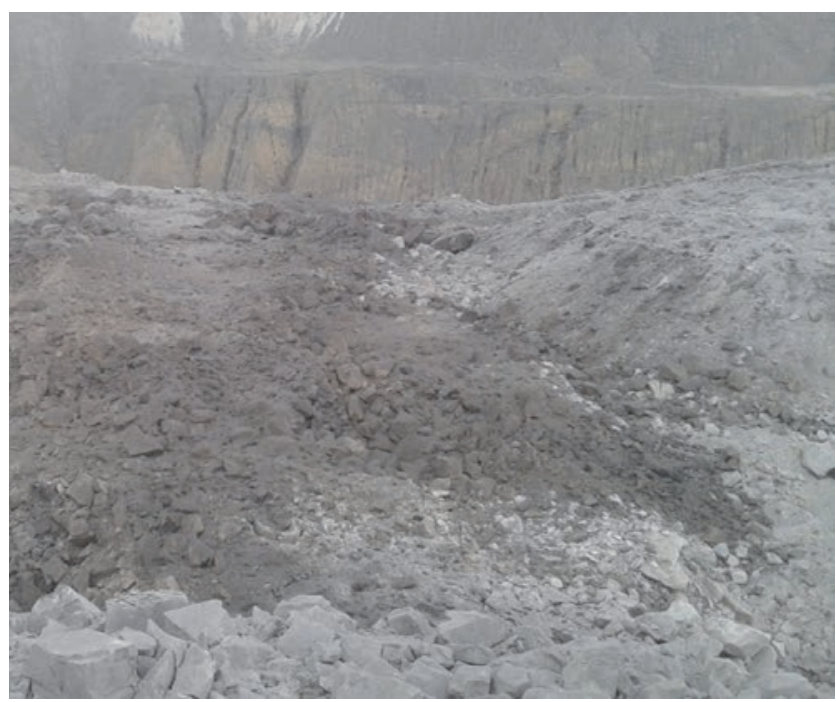

Fig. 3c. Post blast picture of East D1 bench, Jayant Project blasted on dt.28.10.15 
Table 1. Summary of Blast Results ( NCL Jayant Project)

\begin{tabular}{|c|c|c|c|c|}
\hline SL & PARAMETERS & \multicolumn{3}{|c|}{ DETAILS } \\
\hline 1 & Date of blast & $08 / 11 / 2015$ & $28 / 10 / 2015$ & $01 / 05 / 2016$ \\
\hline 2 & Type of blast & $\mathrm{D} /$ Cord & e-DET "ft" & e-DET "ft" \\
\hline 3 & Location of Blast & Dragline & Dragline & Dragline \\
\hline 4 & Strata & MHSST & MHSST & MHSST \\
\hline 5 & Hole Dia. $(\mathrm{mm})$ & 269 & 269 & 269 \\
\hline 6 & No of holes & 40 & 37 & 19 \\
\hline 7 & $\begin{array}{l}\text { Hole depth (m) } \\
\text { (Avg.) }\end{array}$ & 35.81 & 37.00 & 30.33 \\
\hline 8 & $\begin{array}{l}\text { Bench height } \\
\text { (m)Avg. }\end{array}$ & 34 & 34 & 27 \\
\hline 9 & Burden (m) & 10 & 10 & 10 \\
\hline 10 & Spacing (m) & 10 & 10 & 10 \\
\hline 11 & $\begin{array}{l}\text { Total Area Blasted } \\
\mathrm{m}^{2} / \text { hole }\end{array}$ & 3331 & 3120 & 1600 \\
\hline 12 & Total Volume $\left(\mathrm{m}^{3}\right)$ & 113254 & 106080 & 43200 \\
\hline 13 & $\begin{array}{l}\text { Average charge per } \\
\text { hole }(\mathrm{kg})\end{array}$ & 1823.64 & 1829.13 & 1455.29 \\
\hline 14 & $\begin{array}{l}\text { Total bulk expl. } \\
\text { Charge }(\mathrm{kg})\end{array}$ & 72809 & 67557 & 27597.25 \\
\hline 15 & $\begin{array}{c}\text { Total cast } \\
\text { booster }(\mathrm{kg})\end{array}$ & 136.75 & 120.75 & 53.25 \\
\hline 16 & $\begin{array}{l}\text { Total explosive } \\
\text { charge }(\mathrm{kg})\end{array}$ & 72945.75 & 67677.75 & 27650.50 \\
\hline 17 & $\begin{array}{l}\text { Insitu powder factor } \\
\qquad\left(\mathrm{m}^{3} / \mathrm{kg}\right)\end{array}$ & 1.55 & 1.57 & 1.56 \\
\hline 18 & $\begin{array}{l}\text { Bulk explosives } \\
\text { manufactured by }\end{array}$ & IOCL & IOCL & IOCL \\
\hline 19 & Fragmentation & Good & Excellent & Excellent \\
\hline 20 & Throw & Normal & Normal & Normal \\
\hline 21 & Fly rock & Minimum & Negligible & Negligible \\
\hline 22 & $\mathrm{PPV}(\mathrm{m} / \mathrm{s})$ & 2.19 & 2.03 & 1.73 \\
\hline 23 & $\begin{array}{l}\text { Location of } \\
\text { vibrograph }\end{array}$ & $\begin{array}{l}\text { Morwa } \\
\text { Thana }\end{array}$ & $\begin{array}{l}\text { Bhagat Singh } \\
\text { Colony }\end{array}$ & Madhauli \\
\hline 24 & Frequency $(\mathrm{Hz})$ & 8.0 & 8.1 & 6.0 \\
\hline & & & & \\
\hline
\end{tabular}

B. Techno-Economic Analysis and Advantages Over Conventional D/Cord System

The following benefits observed by Jayant Project, NCL, using electronic detonators:

1. Fragmentation improved using e-DET $\mathrm{ft}$, even while operating at the same powder factor (PF). This aspect was found from relative productivity improvement in dragline operations (Detailed Analysis is given in Table 1 .

2. Better blast efficiencies / fragmentation have been acknowledged by persons operating Dragline Section. Ease in mucking, ease in digging and handling had been reported by Dragline operational group. It will reduce the effective cycle time of
Dragline operation due to ease in filling dragline bucket (Fig 3a, 3b and 3c).

3. Better blast control using electronic detonators noticed by Jayant Project. There No complaints reported from local residents living in the vicinity of the mine boundary.

4. Dragline break downtime found reduced while handling blasts, conducted using electronic detonators. It is being envisaged that there will be an increase in life of Dragline bucket, its tooth points, adaptors and drag/hoist rope during operations, for reasons off better blast fragmentation and muck-pile looseness.

5. Side casting to the extent of $50 \%$ is achievable , using electronic detonators if block dimensions \& $\mathrm{L} / \mathrm{W}$ ratio is in the ratio of $3: 1$.

\section{CONCLUSIONS}

From the initial results of blasts using electronic detonators in Dragline benches, it was found, that the electronic detonators helps in improving mining efficiency \& safety. It reduces Ground Vibration, Fly rock \& Noise.

Electronic detonators are extremely important tools for tomorrow's blasting needs in varied conditions for the reason they are precise in delay timing, field programmable, and much safer to use. They can reduce mining costs, increase productivity when used technically correct. They can help mines in blast control and thus meet difficult environmental conditions.

\section{ACKNOWLEDGEMENT}

The authors thank their respective organizations for granting permission to present this paper. The views expressed are purely of the authors and not necessarily of the organization they represent.

\section{REFERENCES}

[1] M.O. Sarathy, 'Explosive-Rock Interaction-A Review': Reading material distributed by GOCLCL in 'Workshop on Blasting Efficiency - Mining Costs', Hyderabad June 2010.

[2] M.O. Sarathy, - 'True Bottom Hole Initiation and Use of Precision Elelctronic Detonators $e$-DET and $e$-DET $\mathrm{ft}$ " : Tools for Optimum Bench Blasting. Journal of Mines, Metals \& Fuels. NovemberDecember 2014. 